\title{
Valuing a natural gas pipeline expansion project: A copula-TGARCH application in Mexico
}

\author{
Valorando un proyecto de expansión de ductos de gas natural: \\ Una aplicación copula-TGARCH en México
}

\author{
Ricardo Massa Roldán ${ }^{1 *}$ and Montserrat Reyna Miranda ${ }^{2}$ \\ ${ }^{1}$ CONACYT - Centro de Investigación y Docencia Económicas, México \\ ${ }^{2}$ Tecnológico de Monterrey, México
}

Received April 5, 2017; accepted January 9, 2018

Available online November 14, 2018

\begin{abstract}
With the liberalization of energy prices and the opening of the energy sector to competitors in Mexico, an opportunity for new investment projects is now open. Due to the current conditions of international energy markets, such as volatility and low prices with no prospect of reversion, a need for valuation tools to better capture the risk and benefits of a project presents itself. We propose a methodology based on the volatility treatment of numerous underlying assets in a Real Options Analysis: using a TGARCH for the individual volatilities and copulas for the joint effect. The methodology is applied to a natural gas distribution project of Mexico's State oil company Petróleos Mexicanos (PEMEX). An estimated net present value of the gas pipeline is provided, considering the real options perspective. The result of our empirical application validates the real option's theory of a higher net present value estimation for the project when incorporating the effect of different sources of uncertainty and non-linear interdependence.
\end{abstract}

JEL Codes: C14, C58, C22, G32, H54.

Keywords: Copula; Heteroskedasticity; TGARCH; Natural Gas; Expansion Real Option.

\footnotetext{
*Corresponding author.

E-mail address: ricardo.massa@cide.edu (R. Massa Roldán)

Peer Review under the responsibility of Universidad Nacional Autónoma de México.
} 


\section{Resumen}

Con la liberalización de precios y la apertura del sector energético a la competencia en México, se presenta una nueva oportunidad para un mayor conjunto de proyectos de inversión. Debido a las condiciones de los mercados internacionales de energéticos, como volatilidad y precios bajos persistentes, se vuelven necesarias herramientas de evaluación que identifiquen mejor los riesgos y beneficios de un proyecto de inversión. En el presente trabajo, proponemos una metodología de valuación basada en análisis de Opciones Reales con múltiples activos subyacentes, usando un modelo TGARCH para modelar la varianza de los activos individuales y cópulas para el efecto conjunto. La metodología es aplicada a un proyecto de inversión en un gasoducto de Petróleos Mexicanos (PEMEX), la empresa petrolera estatal de México. Se proporciona un valor actual neto estimado del gasoducto considerando la perspectiva de las opciones reales. El resultado de la aplicación empírica valida la teoría de opciones reales que establece que el incorporar el efecto de diferentes fuentes de incertidumbre dentro de la valuación resulta en un mayor valor presente neto.

Códigos JEL: C14, C58, C22, G32, H54.

Palabras clave: Cópula; Heteroscedasticidad; TGARCH; Gas Natural; Opción Real de Expansión.

\section{Introduction}

With the promulgation of the Mexican energy bill on December 20th, 2013 and the liberalization of energy prices in the country, the door to investment in energy projects was effectively opened in the country. Private and public companies can now take part in the hydrocarbon, renewable energies and electricity industries in a competitive, efficient and profitable manner. The creation and application of further regulation in order to provide more opportunities to invest in areas such as solar energy generation is underway. However, the most remarkable cases of private-public investments have already happened in fields such as import and distribution of fuel and natural gas.

A relevant factor to consider in the valuation of energy investment projects is the presence of relatively low oil prices and high volatility in other energy prices. These considerations put a strain in investments and call for the development and application of new assessment tools that might lead to more accurate valuations, since small mistakes can mean investment in unprofitable projects or the foregoing of profitable and beneficial ones. When evaluating an investment, one must identify sources of inflows and outflows. Cash flows generated by projects in the energy business in Mexico clearly depend on the prices of the energetic itself but are also intrinsically affected by changes in the USD-MXN exchange rate, since prices of commodities are set on international markets and typically denominated in US dollars. It becomes evident that applying any evaluation tool that considers only one source of risk may lead to significant deviations from the real value of investment projects. Moreover, the interaction and possible co-movements among the sources of risk is a factor that could severely affect their results. In the present work, we propose a methodology for the evaluation of projects based on real options with multiple underlying assets, and we apply the proposed methodology to the valuation of the natural gas distribution project "Los Ramones" of Petróleos Mexicanos (PEMEX hereafter), the Mexico State-owned oil company. 
Real options with multiple underlying assets are not a new construct, but the approach taken towards accounting for the interaction among the underlying assets is a novelty of our work. In its first stage, the proposed methodology estimates the individual volatility of the underlying assets using a TGARCH model. Then, their joint effect is captured through the use of copulas. Finally, the resulting elements are used as inputs to perform the valuation of the project in the context of real options. The application case was chosen due to the importance of PEMEX in the industry; particularly, the size of its budget, as well as the relevance of the project nationwide. PEMEX and its subsidiaries have a limited budget to invest in profitable projects; being able to accurately find the most convenient ones is crucial for the company and, due to its size and participation, for the entire industry. Furthermore, the 2013 energy bill provided new grounds for joint collaborations between the private and public sectors for energy related investments. "Los Ramones" became one of the most outstanding first examples within this new open-market environment.

PEMEX is the 15th world's producer of natural gas. However, one of its main obstacles is the national distribution of this energetic [PEMEX (2013)]. To address the problem, in early 2015, the company was considering an investment project to expand the National Gas Pipeline System (SNG for its acronym in Spanish) by increasing the natural gas distribution in the country, mainly in the central-west area. The project is known as "Los Ramones Natural Gas Pipeline" and is designed to transport natural gas from the U.S.A.-Mexico border to the central part of the country. The underlying assets considered were the USD-MXN exchange rate and the international price for natural gas. To the best of our knowledge, there has been yet no application of Copula-TGARCH methodology into the ROA context considering the effect that two (or more) underlying assets may have over the value of this project.

This paper is organized as follows: in Section 2, a review of the body of works on real options is presented. Section 3 describes the methodology. The application is detailed in Section 4, while Section 5 contains the results. Finally, Section 6 presents concluding remarks.

\section{Real options analysis}

When addressing the valuation of investment projects, there is a generalized trend to apply traditional approaches based on the discount cash flow (DCF hereafter) such as net present value. Even though these techniques have been criticized because of they don't precisely fit the existent business environment [Myers (1984); Trigeorgis and Mason (1987); Kulatilaka (1995); Ross (1995)], they are still the most commonly used tools of investment project valuation. The real options analysis (ROA hereafter) provides a framework as to how the valuation of investment projects can be managed so to address the current business conditions and improve the results presented in traditional valuation techniques, particularly the treatment of uncertainty and strategic thinking. Mun (2006) points out that the ROA is a technique that systematically incorporates financial theory, economic analysis, management science, decision science, statistics, and econometric modeling into the application of the option pricing theory as a valuation tool of real assets.

In general terms, the main advantage of the ROA follows two directions: how it overcomes the obstacles presented under the traditional DCF techniques, and its capacity to quantify strategic implications into the valuation process. Even though the benefits of the ROA-as a superior investment decision valuation approach in the presence of uncertainty and irreversibility-are 
clearly stated [Leslie and Michaels (1997); Luehrman (1998; 1998a); Amram and Kulatilaka (1999; 1999a); Dixit and Pindyck (1994; 1995); Copeland and Keenan (1998;1998a)] there is still a general reluctance to use it in the practitioner world. This can be explained either by its complexity -as not all managers master the mathematical tools needed in the approach-, or by its accentuated use in the commodity markets such as gold, gas, and oil. What most critics of this approach argue is that the examples and assumptions used in research and applications lack real life characteristics because they are seen more as an academic exercise rather than a business decision tool. As an example of an over-simplification of real situations, most of the ROA research and application focuses on the presence of one underlying asset. However, options rarely arise in isolation; most of the time, investment projects depend on more than one underlying asset, or even distinct projects.

The beginning of the rainbow option analysis (one with multiple underlying assets) can be traced back to the work of Margrabe (1978), who evaluated a European option to exchange one asset for another. His idea was further developed by Stulz (1982), where analytical formulas are presented for pricing a put and call European option considering the maximum or the minimum of two risky assets. He transformed the double integral of the bivariate density function into a cumulative bivariate normal distribution. These results showed that a call option on the minimum of two risky assets, considering zero as exercise price, can be evaluated with the same formula used to price an option to exchange one asset for another. Johnson (1987) extended the results in order to define a solution for the general case of an option on several assets through an intuitive approach founded on the Black-Scholes formula. The inclusion of these ideas in the ROA context has led to an expansive research trend. For example, Sødal et al. (2008) modeled, under the valuation of a switching option context, the price spread as a mean-reverting process between the co-integrated dry and wet bulk markets for a combination carrier. Pimentel et al. (2008) used a high-speed rail project to develop a partial differential equation model to address the impact multiple sources of uncertainty have over the optimal investment decision, hence, over the valuation process. More recently, Miranda and Brandão (2014) studied the impact an investment has on the value of the company when the firm has the option to defer, abandon, or expand a mining project. Using a Monte Carlo regression method and a control randomization technique, Chen et al. (2016) explore the valuation problem of a mining project when fixed levels of production are imposed. Georgiopoulos (2017) analyzes the capital structure decision for investment projects with high level of uncertainty, exemplified with oil exploration projects.

Recognizing and accounting for multiple underlying assets is only the first step to introducing a realistic perspective into the ROA analysis. For it to be included in the valuation model, the key determinant must be the treatment of the relationship that exists in the multiple underlying assets, either as a dependence structure or as a measure of association. Dockendorf and Paxson (2010) developed two sequential rainbow option models, one for the better of two stochastic assets, and the other on the mean-reverting spread between two co-integrated assets. Moreover, they incorporated two sources of uncertainty into the ROA valuation by working on the spread of two co-integrated variables into a continuous rainbow option model. Despite their work, few efforts have been made in order to develop a "rainbow real option" approach. In line with the inclusion of several sources of uncertainty, Qiu and Wang (2014) conducted a multi factor analysis in deep-water oil and gas investments in order to address the impact financial, geological and engineering aspects have on the value of a project. It is important to 
note that for infrastructure projects concerning new technologies and/or long periods to begin operation, including multiple uncertain factors into the decision to build is fundamental when a set of realistic conditions about the market is to be considered. This is because even though the investment decision is made, the dynamics of the underlying cash flows may alter the feasibility of a project during its building time. In that sense, Kauppinen et al. (2016) present an extension to the Majd and Pindyck (1987) work in which the time-to-build real option incorporates the dynamic of two sources of uncertainty. The authors explore the effect these sources have on the selection of the optimal threshold boundary for high cost investments. In light of the increasing public-private partnerships for investment in energy projects, Adkins and Paxson (2016) propose the use of collar options as instruments to guarantee a lower bound (floor) while providing the opportunity to capture abnormally high returns. This type of pricing arrangement significantly reduces risk, leads to an earlier investment exercise, and increases the investment option value.

Conceptually, volatility illustrates the uncertainty factors that do not dissolve during the projects' lifetime. Following Amram and Kulatilaka (1999), volatility is treated as a constant in the ROA approach, making real options virtually unaffected by unexpected changes in riskiness during the lifespan of the project. Another common practical error is to use the terms risk and uncertainty interchangeably, which is, as described by Hung and So (2011), a direct source of valuation inaccuracies. In order to differentiate them, they propose a method to filter the risk of the project without the influence of uncertainty, using an adjusted Black-Scholes pricing formula.

One tool that has gained acceptance for the treatment of multiple sources of uncertainty is the copula modeling. Literature on the copula founding concepts, statistical properties, and financial applications has developed rapidly. Joe (1997) and Nelsen (1999) are excellent and highly technical introductory texts, whilst Frees and Valdez (1998) provide an introduction to the statistical properties of copulas and their applications to the actuarial world. Bouyé et al. (2000) cover relevant material on copula application in financial econometrics. During the last fifteen years, there has been a significant expansion of academic literature regarding the application of copula modeling in the bivariate and multivariate financial context, and an important effort has been made to expand its application into ROA. A noteworthy effort to enhance this trend is found in Cherubini and Luciano (2002, 2002a), who make a comprehensive description on how to price bivariate and multivariate digital options trough copula modeling. This work led to an interesting development, focused on rainbow options, presented in Cherubini et al. (2004).

The application of copula models into the real options theory and decision-making under uncertainty in the context of new investments in power generation technologies is gaining popularity. The main reason is that energy derivatives tend to present non-linear dependencies as a consequence of increasingly intertwined commodity markets. Armstrong et al. (2004) used an Archimedean copula-based model to include technical uncertainty in the valuation of expansion projects in the oil industry. Grégoire et al. (2008) studied the dependence structure between prices for futures on crude oil and natural gas using a copula approach and discussed an appropriate copula family selection for these markets. In that sense, Denault et al. (2009) used a copula model to analyze the diversification effect of energy generation plants when considering a combination of inflow: they resolved the risk value of a project that considers a mixed hydroand-wind generator as lower than one that considers an all-hydro project. Valizadeh et al. (2010) developed a copula approach to study the planning and operation characteristics of 
renewable energy generation in Iran. Even though Fleten and Näsäkkälä (2010) did not work within the copula-modeling environment, they developed an interesting model to determine thresholds for energy prices where it is optimal to make an investment decision in gas-fired power plants under the ROA context.

In terms of considering multiple underlying assets as determinants for the valuation of an investment project, Herath et al. (2011) applied the copula methodology to price refinery crack spread options, i.e. the purchase (sale) of crude oil against the purchase (sale) of refined petroleum products. This is used as a base for risk management in volatile commodity markets that enable refiners to hedge their operating margins while allowing them to participate in any future widening of their refining margins. They concluded that a Clayton copula model is more appropriate to describe this particular spread option. Benth and Kettler (2006) present a similar approach; they developed a non-symmetric copula to model the spark spread options, or the comparison between electricity and natural gas prices, following a bivariate non-Gaussian autoregressive process. Similarly, Westner and Madlener (2010) applied a specific spread copula-based real options approach, defined as the difference between the price of the output -electrical power- and the costs of the input factors (e.g. fuels), in order to determine whether an investment project in a power generation plant should work without heat utilization technology or combining heat-and-power (CHP). By using the contribution margin that a plant operator earns for converting fuel into power, they showed that power plants with CHP generation present a lower real option value than those without heat utilization.

As noted, instead of working with the underlying assets, the copula modeling approach considers the combination of financial options and/or real options. On the other hand, the described option valuation approach uses the spread to describe the dependence structure of underlying assets. The present work describes a methodology to deal with the volatility of two or more underlying assets in the context of the ROA, which is described in next section.

\section{Methodology}

\section{Copula modeling}

The association between random variables has been one of the most studied concepts in statistics and probability in the financial context. Association is typically measured through the Pearson coefficient, widely known as the linear correlation measure. Its characteristics and assumptions fail when applied in the financial environment, especially those regarding nonlinearity and non-normality properties of the series. It becomes clear that, in trying to maintain the intention of the ROA, the inclusion of other association measures is needed. Due to its characteristics, copulas constitute an alternate measure of stochastic dependence, which addresses the limitations of the correlation as a dependence measure. Embrechts et al. (2002) offer an eloquent and detailed coverage of the dependence concept and its treatment trough copulas. As for its application in the financial context, Chen et al. (2004) provided two simple goodness-of-fit tests so as to apply copula models to multivariate financial time series. Copula modeling represents an appropriate alternative as they offer a non-parametric, scale-invariant measure, which is independent from the margins' distributions.

The copula concept was introduced by Sklar (1959) as a tool to model the dependence between random variables, he states that if $F_{j}\left(x_{j}\right)$ is the CDF of a univariate continuous random variable $X_{j}$ then $H\left(x_{j}\right)=C\left(F_{1}\left(x_{1}\right), \ldots, F_{n}\left(x_{n}\right)\right)$ is an n-variate distribution for $X=\left(X_{1}, \ldots, X_{n}\right)$ 
with marginal distributions $F_{j}$ for $j=1, \ldots, n$. Conversely, if $F$ is a continuous n-variate CDF with univariate marginal $F_{1}, \ldots, F_{n} \mathrm{CDFs}$ then there exists a unique n-variate copula $C$ such that $F\left(x_{1}, \ldots, x_{n}\right)=C\left(F_{1}\left(x_{1}\right), \ldots, F_{n}\left(x_{n}\right)\right)$. That means that any choice for the marginal distributions will be consistent with the copula approach, but also, that the resulting function will provide a separated description of the margins and their dependence structure. This conclusion represents an attractive feature that directs practitioners to its application in finance. A fundamental element in dependence structures within the copula construction is the bound concept [Hoeffding (1940); Fréchet (1957)]. Consider a copula $C(u)=C\left(u_{l}, \ldots, u_{d}\right)$, the Fréchet-Hoeffding bounds are defined by

$$
\max \left\{\sum_{i=1}^{d} u_{i}+1-d, 0\right\} \leq C(u) \leq \min \left\{u_{1}, \ldots, u_{d}\right\}
$$

Therefore, according to this definition, every bivariate copula has to lie inside the surface given by the lower bound (counter monotonicity copula) $C\left(u_{1}, u_{2}\right)=\max \left(u_{1}+u_{2}-1,0\right)$ and the upper bound $C\left(u_{1}, u_{2}\right)=\min \left(u_{1}, u_{2}\right)$. The reason for this is the presence of extreme cases of dependency. Dependence properties and measures of association are interrelated. The most known scale-invariant measures of association are the Kendall's tau and the Spearman's rho rank correlation, both measures of concordance. The concordance concept describes that the probability of having simultaneous large (small) values for $X$ and $Y$, is high, while having an opposite value is low. The Spearman's rho can be interpreted as a measure of average quadrant dependence while the Kendall's tau can be as an average of likelihood ratio dependence. In the present work we focus on the latter. Nelsen (1999) showed that the Kendall's tau and the Spearman's rho could be expressed as

$$
\begin{aligned}
& \tau_{C}=\tau_{X, Y}=4 \iint C(u, v) d C(u, v)-1 \\
& \rho_{C}=\rho_{X, Y}=12 \iint C(u, v) d u d v-3
\end{aligned}
$$

As noted by Capéraà and Genest (1993), the bounds for the Kendall's tau and Spearman's rho can be narrowed when one random variable presents a left tail decreasing behavior while the other shows a right tail increasing one.

Several copula families exist, but the most commonly found in financial applications are Archimedean copulas. Their main feature is that they commonly present closed-form expressions and are consistent with bivariate extreme value theory as they are inherently fitted to work with tail dependence. For this reason, the present work focuses on four oneparameter Archimedean copulas: Frank, Tawn, Clayton, and Gumbel copula families; with particular emphasis on the last two as they exhibit asymmetric dependence. We also include the estimations obtained with the Normal and Student's $t$ copulas to illustrate the case when low tail dependence is found. An extensive description of the entire set of this class can be found in Joe (1997) and Nelsen (1999).

The Frank (1979) copula takes the form.

$$
C\left(u_{1}, u_{2} ; \theta\right)=-\theta^{-1} \log \left\{1+\frac{\left(e^{\left.-\theta u_{1}-1\right)\left(e^{-\theta u_{2}-1}\right)}\right.}{e^{-\theta}-1}\right\}
$$


The dependence parameter $\theta$ may take any real value in $(-\infty, \infty)$. This copula is popular because it allows negative dependence between the margins, and $\theta$ is symmetric in both tails, akin to the Gaussian and Student-t copulas. Still, under this copula, the strongest dependence located in the middle of the distribution making it better suited for margins that exhibit weak tail dependence.

The Clayton (1978) copula takes the form,

$$
C\left(u_{1}, u_{2} ; \theta\right)=\left(u_{1}^{-\theta}+u_{2}^{-\theta}-1\right)^{-1 / \theta}
$$

The dependence parameter $\theta$ may take any real value in $(-\infty, \infty)$. This copula is popular because it allows negative dependence between the margins, and $\theta$ is symmetric in both tails, akin to the Gaussian and Student-t copulas. Still, under this copula, the strongest dependence located in the middle of the distribution making it better suited for margins that exhibit weak tail dependence.

The Clayton (1978) copula takes the form,

$$
C\left(u_{1}, u_{2} ; \theta\right)=\exp \left(-\left(\tilde{u}_{1}^{\theta}+\tilde{u}_{2}^{\theta}\right)^{1 / \theta}\right)
$$

Where $\tilde{u} j=-\log u j$ and $\theta$ being restricted to $[1, \infty)$. Similar to the Clayton copula, it describes positive association only. Yet, it presents strong right tail dependence (upper tail) and relatively weak left tail dependence. Consequently, it is an appropriate copula to be applied when $u_{1}$ and $u_{2}$ are expected to be strongly correlated at high values but less at low ones.

Tawn (1998) introduces an extension of the Gumbel copula, known as the asymmetric logistic copula or the Tawn copula, and has the following dependence function

$$
A(t)=1-\beta+(\beta-\alpha) t+\left[\alpha^{r} t^{r}+\beta^{r}(1-t)^{r}\right]^{1 / r}
$$

Where $0 \leq \alpha, \beta \leq 1$ and $r \geq 1$. This is not an archimedian copula, but rather an extreme-value one. Among other characteristics, Tawn mentions the importance of this asymmetric copula for its application in risk management of investment portfolios and credit portfolios when extremevalues are considered, for example a financial loss due to meteorological events.

One of the most challenging tasks in copula modeling is the correct method selection in order to fit observed market data. It is important to note that there is no definitive rule for copula selection. When selecting a copula, it is very important to acknowledge that the nature of the dependence structure has to be the determinant argument in order to allocate a specific functional form to the relationship. As noted by Frees and Valdez (1998), identifying the appropriate copula family is not a trivial task. In most financial applications, the real challenge consists in finding a convenient distribution to fit some stylized facts expected for the underlying asset behavior.

Due to the characteristics of the copula function, much of the classical statistical theory cannot be used as part of its estimation process. This is commonly developed in the bivariate independent and identically distributed context through asymptotic maximum likelihood estimation. The most used in the literature are the exact maximum likelihood, inference for the margins, canonical maximum likelihood, and non-parametric. [Cherubini et al. (2004)] Therefore, the final selection is commonly derived from the analysis of several distribution 
functions and the comparison of which one yields the best fit according to the provided information. Yan (2007) proposes three estimation methods, from which this work uses the one not assuming any particular marginal distribution for the underlying variables and obtained them from individual TGARCH. As noted by Patton (2006; 2006a) and Chiou and Tsay (2008) this two-step perspective yields asymptotically efficient estimates.

\section{Volatility modeling}

As described in the ROA context, the main problem to address when dealing with two or more underlying assets is the treatment of their joint effect in the volatility of the project. It is widely known that financial time series exhibit clustering and negative correlation with returns (leverage effect). To account for this effect Engle (1982) first introduced the autoregressive conditional heteroskedasticity model ARCH, and Bollerslev (1986) introduced the generalized autoregressive conditional heteroskedasticity models GARCH. Instead of working with the basic GARCH model, in the present work we make use of the threshold GARCH (TGARCH hereafter) model. Acknowledged after the work of Zakoian (1994), but also developed by Glosten et al. (1993), it is commonly used to handle the leverage effect presented in financial time series. A TGARCH $(m, s)$ model assumes a similar ARMA structure than the GARCH model, but the process for the volatility takes the form:

$$
\sigma_{t}^{2}=\alpha_{0}+\sum_{i=1}^{s}\left(\alpha_{i}+\gamma_{i} I_{t-i}\right) u_{t-i}^{2}+\sum_{j=1}^{m} \beta_{j} \sigma_{t-j}^{2}
$$

Where $I_{t-i}$ is an indicator for negative $u_{t-i}$, that is,

$$
I_{t-i} \begin{cases}1 & \text { if } u_{t-i}<0 \\ 0 & \text { if } u_{t-i}>0\end{cases}
$$

$a_{i}, \gamma_{i}$ and $\beta_{i}$ are non-negative parameters satisfying conditions similar to those of GARCH models. From the model, it is seen that a positive $u_{t-i}$ contributes $\alpha_{i} u_{t-i}{ }^{2}$ to $\sigma_{t}{ }^{2}$, while negative $u_{t-i}$ impacts in $\left(a_{i}+\gamma_{i}\right) u_{t-i}^{2}$ with $\gamma_{i}>0$. This way the indicator will capture the leverage effect of the financial series; a consideration missing in GARCH models. For the empirical application, both series considered a TGARCH $(1,1)$ model following the form:

$$
\begin{gathered}
r_{i t}=\mu_{i}+u_{i t} \\
u_{i t}=\sigma_{i t} \varepsilon_{i t} \\
\sigma_{i t}^{2}=\alpha_{i 0}+\alpha_{i 1} u_{i t-1}^{2}+\beta_{i} \sigma_{i t-1}^{2}+\gamma_{i} I\left(u_{i t-1}<0\right)
\end{gathered}
$$

Where innovations $\varepsilon_{i t}$ are assumed to follow a standardized t-student distribution with $\mathrm{v}$ degrees of freedom. The joint volatility treatment will be discussed in detail in the next subsection, where the methodology is described.

\section{Proposed methodology}

The objective of this work is to exploit the advantages of the volatility treatment through the TGARCH model and the dependence structure determination through copula modeling in order 
to apply them in the ROA context. The general idea of this methodology can be summarized in three steps.

1. Individual TGARCH models are used to determine the volatility and terminal value of each one of the underlying assets.

2. The residuals of the models adjusted in the precious step are calculated and used to determine a measure of association between the underlying assets, be it the Kendall tau and the Spearman rho, as adequate.

3. The information gathered in the two previous steps is taken as input for a model of Real Option Valuation. In order to do so, a last element is needed: the joint volatility.

As aforementioned, the volatility treatment with multiple underlying assets is typically made through a spread perspective. Instead of working with the volatility of the spread of two variables, this work considers the volatility of the product of these two variables. This is the main novel element in the Copula-TGARCH real option literature. Its treatment then is made through:

$$
\operatorname{Var}(x y)=\operatorname{Cov}\left(x^{2}, y^{2}\right)-2 \rho \sigma_{x} \sigma_{y} \mu_{x} \mu_{y}-\rho^{2} \sigma_{x}^{2} \sigma_{y}^{2}+\sigma_{x}^{2} \sigma_{y}^{2}+\sigma_{y}^{2} \mu_{x}^{2}+\sigma_{x}^{2} \mu_{y}^{2}
$$

Where $\mu \_\mathrm{x}$ and $\mu \_\mathrm{y}$ represent the expected value of the log-return series, $\sigma_{x}$ and $\sigma_{y}$ the volatility measure of the individual underlying asset, obtained from the TGARH models, and $\rho$ is the measure of association obtained through copula modeling (Spearman's rho).

In practice, most real option problems must be solved using numerical methods. In terms of the valuation procedure, generally there are two types of numerical techniques that are used: the ones that directly approximate the stochastic process of the underlying asset, and those approximating the resultant partial differential equations (PDE's). The most representative solutions under the ROA perspective are: path-dependent simulation, closed-form models, PDE's, and binomial/multinomial approaches. The advantage of these solutions is that they not only provide a value for the project, but also illustrate the optimal strategy to follow in the investment opportunity. Their selection relies on the project's characteristics; the most straightforward solution is the binomial/multinomial approach while the Monte Carlo simulation and PDE's are, somewhat, more complicated methods.

As a summary, for the purpose of this work, an initial estimation of a TGARCH $(1,1)$ model was performed on the individual log-return series of each underlying asset, the natural gas price and the USD-MXN exchange rate. Their resulting residuals series and individual volatilities were saved and used for the copula-fitting step. For it, the libraries rugarch, copula and vinecopula from R software were used to estimate six copulas: Normal, Student's t, Clayton, Gumbel, Frank and Tawn. Finally, the information obtained in the previous steps is being used as input in the ROA context for the valuation of an expansion real option in order to determine its feasibility. A comparison with the official valuation is then performed in order to illustrate the advantages of the proposed methodology.

For the final step, as suggested by Brandão et al. (2005), the binomial option valuation model will be used to determine the value of the investment project. Cox et al. (1979) developed a discrete time lattice-based model with the intention to provide a simple representation of the evolution of the underlying asset value and how it generates a change in the option's value. The fact that this multiplicative binomial model of uncertainty for European options without 
dividends converges with the Black-Scholes formula values as the number of time steps increases is noteworthy. It is neither the scope of this section, or this work, to compare the abovementioned tools, but to illustrate how the valuation process is taken under this perspective.

\section{Project description: Los Ramones natural gas pipeline}

Pemex Gas y Petroquímica Básica (PGPB hereafter), a branch of PEMEX, through its subsidiary, Mex Gas International Enterprises, Ltd (MGI), was considering, in early 2015, the investment project to expand the National Gas Pipeline System (SNG for its acronym in Spanish) by increasing the natural gas distribution in the country; mainly in the centralwest area. The project is known as "Los Ramones Natural Gas Pipeline" and is designed to transport natural gas from the U.S.A.-Mexico border (between Texas and Tamaulipas) to Aguascalientes, Querétaro and Guanajuato. PEMEX estimated that the project would provide approximately $23 \%$ of the natural gas consumption of the Midwest region, encompassing the states of Aguascalientes, Colima, Guanajuato, Jalisco, Michoacán, Nayarit, Querétaro, San Luis Potosí and Zacatecas [PEMEX (2015)].

PEMEX is the 15th world's producer of natural gas. However, one of its main challenges is distribution at a national level. To cope with this problem, the investment project was designed in two phases. In a broad perspective, "Los Ramones I" focuses on transportation of the natural gas imports from United States to the northern part of the country, while "Los Ramones II" focuses on distribution of both national and foreign production to the Midwest. For the construction of "Los Ramones I", PGPB signed a long-term transport service contract with the company Gasoductos del Noreste to build a 48-inch diameter and 116.4-kilometer length pipeline running from Agua Dulce, Texas to Los Ramones, Nuevo León. The operation of "Los Ramones I" started in December 2014 with the objective of increasing the transport capacity by 1.0 billion cubic feet per day (Bcfpd). An additional construction of two compression stations was made in order to raise the capacity up to $2.1 \mathrm{Bcfpd}$, which started operations on December 2015. PEMEX reported that total investment for the construction of the pipeline and the two compression stations was approximately USD \$587 million [PEMEX $(2015 ; 2016)$ ].

The second segment of this investment project focuses on the supply of natural gas to Central and Western Mexico, running from Los Ramones, Nuevo León to Apaseo el Alto, Guanajuato. For construction, financing and operative purposes, the project was divided into two sections: "Los Ramones II North" and "Los Ramones II South". TAG Pipelines, an indirect subsidiary of PGPB, is in charge of the development of the second segment through joint ventures for each of these stages. "Los Ramones II North" runs from Los Ramones, Nuevo León to San Luis Potosí, San Luis Potosí for a total of $452 \mathrm{~km}$ and a USD \$1,563 million investment. "Los Ramones II South" is a 291-kilometer pipeline that runs from San Luis Potosí, San Luis Potosí to Apaseo el Alto, Guanajuato. The investment requirement is USD \$947 million. Operations began in 2016 for the northern section and in 2017 for the southern part. The construction of both sections was scheduled to be somewhat simultaneous, eliminating the possibility of analyzing "Los Ramones II North" and "Los Ramones II South" as time-to-built real option. Therefore, the investment project is considered as a whole and its valuation is performed under the expansion real option context. 
Table 1

Los Ramones Natural Gas Pipeline Project Summary

\begin{tabular}{|c|c|c|c|}
\hline Phase & Description & Estimated Cost & Operational \\
\hline Los Ramones I & $\begin{array}{l}\text { USA-Mexico Border - Los Ramones } \\
116 \text { kilometers of } 48 \text {-inch pipeline } \\
\text { Additional Compression } \\
\text { Extra capacity: } 2.1 \mathrm{Bcfpd}\end{array}$ & $\begin{array}{l}\$ 587 \text { million USD } \\
\text { (Combined) }\end{array}$ & $\begin{array}{l}\text { Dec 2014: } \\
\text { Pipeline }\end{array}$ \\
\hline Los Ramones II North & $\begin{array}{l}\text { Los Ramones - San Luis Potosí } \\
452 \mathrm{~km} \text { of } 42 \text {-inch pipeline } \\
\text { Additional Compression } \\
\text { Extra capacity: } 1.43 \mathrm{Bcfpd}\end{array}$ & \$1 563 million USD & $\begin{array}{l}\text { Dec 2015: } \\
\text { Compression Stations }\end{array}$ \\
\hline Los Ramones II South & $\begin{array}{l}\text { San Luis Potosí - Guanajuato } \\
291 \mathrm{~km} \text { of } 42 \text { and } 24 \text {-inch pipeline } \\
\text { Extra capacity: } 1.353 \mathrm{Bcfpd}\end{array}$ & \$947 million USD & $\begin{array}{l}2016 \\
2017\end{array}$ \\
\hline
\end{tabular}

Source: Own elaboration with information from PEMEX (2015; 2016).

Table 1 summarizes the three segments of "Los Ramones investment project". The project valuation is conducted considering the situation of "Los Ramones II" (North and South) compared to "Los Ramones I". PEMEX originally considered additional investments after the completion "Los Ramones II" between 2018-2022. Because no public information has been released describing those phases, however, they are not considered in the valuation done by the present work. The two underlying assets used in this work are the United States Dollar (USD)-Mexican Peso (MXN) exchange rate and the natural gas price (NGP hereafter). The choice of variables derives from their relevance to the Mexican energy industry. The MXNUSD exchange rate is a key determinant in project evaluation due to the country's geographic location and investment dynamic: most of the information used and presented is commonly expressed in USD rather than MXN. This work uses the indirect quotation (USD-MEX) of the monthly FIX average quote published by the Central Bank of Mexico [BANXICO (2015)] from January 2001 to December 2014 in order to homogenize, in USD terms, the variables used in the valuation process.

The value of the NGP considered in this work is the price of U.S. Natural Gas Pipeline Exports. It is being used as a proxy to the Mexican NGP because the gas industry in Mexico is not sufficiently developed in order to carry out the entire transformation process, consequently, most of the natural gas consumed in the country is being imported from Southern Texas. Therefore, Mexican NGP presents a close behavior with the movement of the U.S. NGP. In addition, as the Energy Ministry of Mexico does not keep record of the evolution of the NGP prior to 2007, a consistent time series for the Mexican case does not exist. The price used is a monthly publication by the US department of energy [EIA (2015)] and expressed in USD per thousand cubic feet. In order to capture the nature of the financial time series, the price of the underlying assets is computed as log-return rates.

\section{Results}

Los Ramones II (North and South) natural gas pipeline investment project is an expansion option, as it will alter the operating scale of the existing infrastructure. This work is considering the product of two underlying assets; therefore, the intrinsic value of this option is: 


$$
\operatorname{Max}\left(\left(\text { Expansion } * e_{U S D-M X N} * P_{N G}\right)-\text { Investment, Continue }\right)
$$

According to the information published by PEMEX, the expansion factor used in the valuation is 2.33 and the investment cost \$2.51 billion USD. The valuation period for this analysis is from 2015 to 2020, being January 2015 the investment decision period. The individual TGARCH models estimated to obtain the long-term volatility of both underlying assets are TGARCH $(1,1)$. Results are reported in Table 2, where it can be noted that all the coefficients are statistically significant at a $5 \%$ level.

Table 3 shows the results obtained by the proposed methodology for the Normal, Student's t, Clayton and Frank copulas. As aforementioned, six copulas were fitted, originally suggested by the optimization algorithms and functions already incorporated in R software: Normal, Student's t, Clayton, Gumbel, Frank and Tawn. However, the Gumbel and the Tawn values are not further reported, since they do not provide a good fit with the available information. The goodness-of-fit (GoF) tests applied, using the software R, were the White test, the Vuong, and the Clark test. The results of the White GoF test for the four remaining copulas are reported in Table 3.

Table 2

Summary of Individual TGARCH Estimations

\begin{tabular}{lcccc}
\hline & \multicolumn{2}{c}{ Natural Gas } & \multicolumn{2}{c}{ USD/MXN } \\
\hline & Coefficient & p value & Coefficient & p value \\
\hline$\mu$ & -0.0068 & 0.0455 & 0.0012 & 0.0394 \\
$\alpha_{0}$ & 0.0430 & 0.0066 & 0.0056 & 0.0137 \\
$\alpha_{1}$ & 0.3927 & 0.0005 & 0.1852 & 0.0107 \\
$\beta$ & 0.3906 & 0.0069 & 0.6209 & 0.0023 \\
$\gamma$ & -0.1461 & 0.0404 & 0.5776 & 0.0269 \\
\hline
\end{tabular}

Source: Own elaboration with data of EIA (2015), PEMEX (2015; 2016) and BANXICO (2015), using rugarch package in the software R.

It is observable that in all cases the probability indicates that we are in the no-rejection area, thus accepting the null hypothesis that the copula fits the data. According to the Vuong and Clarke GoF tests, the Normal copula outperforms all others fitting the provided data. It is interesting to discern that, even though Normal and Student's t copulas do not capture tail dependence, their results are very similar to that of the Clayton copula (when variables exhibit dependence in the lower tail). Both cases yield a positive net present value when considering the ROA valuation, indicating that the project should be accepted. The case of the Frank copula is also peculiar because the strongest dependence is located in the middle of the distribution and, therefore, is known to be better suited for margins that exhibit weak tail dependence, which seems to be the case with the selected underlying assets. When using the results of this copula, the valuation is slightly bigger than with the former three. 
Table 3

Summary of Estimated Results

\begin{tabular}{lllll}
\hline Copula & Normal & Student t & Clayton & Frank \\
\hline White GoF test* & $0.914 * *$ & 0.990000 & 0.828947 & 0.770000 \\
Spearman's rho & 0.045575 & 0.046064 & 0.081817 & 0.330415 \\
Kendall's tau & 0.029024 & 0.029335 & 0.039301 & 0.036673 \\
Joint Volatility & 0.002721 & 0.002721 & 0.002713 & 0.002543 \\
ROA Value@3.76\% & $\$ 2,146,625,639$ & $\$ 2,146,625,963$ & $\$ 2,146,658,658$ & $\$ 2,147,492,880$ \\
ROA Value@5.1\% & $\$ 2,011,561,838$ & $\$ 2,011,562,461$ & $\$ 2,011,625,430$ & $\$ 2,013,233,687$ \\
ROAValue@7.47\% & $\$ 1,794,531,714$ & $\$ 1,794,532,911$ & $\$ 1,794,653,807$ & $\$ 1,797,751,355$ \\
\hline
\end{tabular}

\begin{tabular}{ll}
\multicolumn{2}{c}{ Valuation in the Linear Context } \\
\hline Pearson's rho & 0.043848 \\
Joint Volatility & 0.003280 \\
ROA Value@3.76\% & $\$ 2,145,056,154$ \\
ROA Value@ $5.1 \%$ & $\$ 2,008,585,888$ \\
ROA Value@7.47\% & $\$ 1,789,088,080$
\end{tabular}

ROA value refers to the net present value of the project "Los Ramones II" considering the real option analysis. Values are expressed in USD, taking January 2015 as the decision period and $3.76 \%, 5.10 \%$, and $7.47 \%$ as discount rates. *Indicates the reported p-value of the White goodness of fit test. **According to the Vuong and Clarke tests the copula that provides a better fit for the data is the normal copula, the one that performs the worst is the Student $t$ copula.

Source: Own elaboration with data of EIA (2015), PEMEX (2015; 2016) and BANXICO (2015).

The final objective of the empirical application is to compare the NPV resulting from PEMEX's procedure with the valuation result from the proposed methodology. The expected result for this comparison was to illustrate that, by combining the advantages of the CopulaTGARCH modeling into the ROA context, a higher value for the investment project would be obtained. Unfortunately, despite our efforts to obtain such information, at the time this work was performed the information was unavailable. As detailed by Olmos (2017), the process to obtain up-to-date information regarding the valuation and financial characteristics of "Los Ramones II" project is difficult due to political and legal motives. However, as stated by PEMEX (2015a) and later described by González and García (2015), under the transformation process PEMEX has initiated, their new goal is to disinvest in infrastructure projects in order to concentrate on its nuclear business, exploration and production of hydrocarbons. To do so, PEMEX started selling their share on specific projects; "Los Ramones" I and II are part of this strategy. Following conventional asset pricing theory, the selling price should reflect the present value of the project. Therefore, even though the "official" NPV of the "Los Ramones II" project has not been released yet, one can establish that the amount received by PEMEX for the sale of their share in the project reflects, inherently, the value of the project. PEMEX (2015) reports that they received 1.325 billion USD for their share (50\%) of "Los Ramones I", implicitly stating a project value of 2.65 billion USD. For the case of the "Los Ramones II" project, González and García (2015) reported that PEMEX received 900 million USD for their share $(45 \%)$. Using this figure as the price that represents the proportional value of the project, its intrinsic total value should be around USD \$2 billion. Taking this amount as the best possible approximation of official data and, without knowing more details about the valuation (namely: method used, time considered, and discount rate applied), our approach to compare 
the value of the project is through a sensitivity analysis of the discount rate. In order to do so, we estimated the value of the project considering three discount rates: $3.76 \%, 5.1 \%$ and $7.47 \%$. These rates are proxies for the cost of capital for the project, which would presumably be financed only with debt. The rates represent the cost on PEMEX's outstanding debt, issued around the time the project was undertaken and with a maturity of 5 years. The first one, $3.76 \%$, corresponds to the rate of a floating bond issued on January 2015, at the rate of the T-bill $15 / 8$, maturing on 12/30/2019, plus a spread of 235 basis points. The second one, $5.1 \%$ is the average rate PEMEX was paying on December 2014 for outstanding debt maturing on 2020. And the third rate, $7.47 \%$, is the rate on a fixed bond issued on November 2014, with 5 years to maturity. Data for these bonds was obtained from Bloomberg.

Table 3 also presents the net present value of "Los Ramones" when considering the proposed methodology. It can be seen that, for the four copulas, the project's value surpasses the "official" reported value by about 146 million USD, when a $3.76 \%$ discount rate is considered. For the case of a $5.1 \%$ rate, the incremental value provided by the proposed valuation methodology is around 11 million USD. In the last scenario, when a rate of $7.47 \%$ is considered, all values lie below 2 billion USD. These final results are also interesting in the sense that they may provide a notion of which could the discount rate possibly be in PEMEX's valuation: a value below 7\%. Even though we do not know the valuation technique PEMEX employed, we performed the estimation of the hypothetical rate that needs to be used in our methodology in order to match the "official" NPV. In other words, if a rate of 5.219\% is used along with the Normal and Student's t copulas, our valuation will yield a 2 billion USD NPV, matching the value assumed in this work. For the case of the Clayton copula, this rate is $5.220 \%$, and $5.238 \%$ for the Frank. Finally, is noteworthy that all three implicit rates are close to the average rate PEMEX was paying on December 2014 for outstanding debt maturing on 2020 (5.1\%). Additionally, as a comparison element, we included the valuation of the investment project when only linear measurements are considered. That is, determining the individual volatility through the conventional standard deviation calculation and the Pearson coefficient as the measure of correlation between the underlying assets. The joint volatility is calculated also as in equation (10). Our results are in line with the theoretical aspects of the inclusion of non-linearity into the real option valuation. Overall, the valuation through ROA yields a higher project value. However, when the benefits of the TGARCH and Copula models are included, an additional project value is found when compared to the ROA valuation in the linear context. For the case in which the discount rate is $3.76 \%$ the project value gained by the proposed methodology is around 1.6 million USD. With $5.10 \%$ and $7.47 \%$ the gains are approximately 3 and 5.4 million USD respectively. Our results illustrate the benefits, in terms of project value gains, that the proposed methodology has when compared to conventional considerations in the ROA.

\section{Concluding remarks}

The methodology proposed by this study is an alternative process to value investment opportunities that seeks to harness the benefits of the ROA, TGARCH and Copula models. The main argument is that the three components are best fitted to capture and describe the nature of the financial series. It has been established that the ROA perspective outperforms the traditional valuation techniques as it incorporates flexibility, uncertainty, irreversibility, discipline and strategic perspective into the valuation process. Special attention has been paid to the volatility 
treatment, as it is a fundamental variable in investment project valuation. For doing so, a TGARCH model was used, as it outperforms the traditional volatility models by incorporating the clustering and leverage effect into its value. On the other hand, copula modeling enables the establishment of a correlation structure for variables that are not normally distributed. It provides a flexible tool to analyze nonlinear and asymmetric dependence structures between markets and risk factors, preserving the specification of the individual marginal distributions and eliminating their influence in the joint structure. The bivariate Gumbel and Clayton copulas are useful to work with variables that present tail dependence, a main focus of risk management.

Given the conditions of the Mexican energy markets nowadays and its interaction with international energy markets, the methodology proposed is indeed a useful tool for companies trying to compete in the industry and struggling to find profitable investment opportunities. As an example of how it can be applied, the Mexican natural gas pipeline expansion project "Los Ramones" was evaluated. Our results, aligned to the real options' theory and the literature described in section 2, suggest that identifying and including the multiple sources of uncertainty of a given investment project produces a bigger NPV for the project and, presumably, a more accurate one. Moreover, the inclusion of the Copula-TGARCH modeling to the real options framework for evaluating projects, as opposed to treating the volatility only in a linear context, may add important value from the theoretical point of view as substantiated by the extensive literature on volatility modeling. Our results succeed at showing that applying a CopulaTGARCH methodology for the treatment of the volatility increases the value of the project when compared to the linear-real option alternative. We daresay that the fact that dynamics are better captured when allowing for non-linear, non-constant features in fact leads to additional value of project within the ROA context; however, further research is in order to prove that this is the case.

The proposed methodology certainly has room for improvement; hence, some final recommendations and considerations are made. The use of high frequency data is consistent with the intention of this procedure. Working, for example, with daily information may enhance the properties of the Copula-TGARCH model. For the present work, this type of information was unavailable for natural gas price due to the limited data on the matter. We highly encourage future research to focus on this issue. After reviewing and comparing the energy investment opportunities in the world, as described in section 2, the Mexican energy sector presents lags in terms of the development of projects with a real option perspective, expansion or contraction projects are predominant in the country. New types of real options should be considered in the sector to reinforce its strategic perspective.

Finally, two main expansions are suggested. The methodology used for a bivariate case can be directed to develop multivariate Copula-GARCH models for real option analysis. By doing so, the number of relevant variables considered in the analysis increases, leading to a better possibility of directly capturing their effect in the value of the project. Furthermore, the CopulaGARCH model (in any form) can be enriched by the addition of a discount rate model that adequately estimates and captures the nature of the energy industry, particularly the Mexican one. This will eliminate the arbitrary selection of a discount rate by the manager and increase the possibility of estimating a value for the project that completely, or at least in the maximum possible way, captures and reflects the characteristics of its financial environment. 


\section{References}

Adkins, R., \& Paxson, D. (2016). Real Investments with Collar Options. Annual International Conference. Real Options Group. Oslo/Trondheim, Norway.

Amram, M., \& Kulatilaka, N. (1999). Disciplined decisions: Aligning strategy with the financial markets. Harvard Business Review, 1+2, 95-104. http://doi.org/10.1225/99101

Amram, M., \& Kulatilaka, N. (1999a). Real Options: Managing Strategic Investment in an Uncertain World. Boston, Massachusetts: Harvard Business School Press.

Armstrong, M., Galli, A., Bailey, W., \& Couët, B. (2004). Incorporating technical uncertainty in real option valuation of oil projects. Journal of Petroleum Science and Engineering, 44 (1-2), 67-82. http://doi.org/10.1016/j. petrol.2004.02.006

BANXICO. (2015). Monthly FIX MXN-USD exchange rate. Banco de México. Retrieved April 19, 2016 from http:// www.banxico.org.mx/portal-mercado-cambiario/

Benth, F., \& Kettler, P. (2010). Dynamic copula models for the spark spread. Quantitative Finance, 11 (3), 407-421. http://doi.org/10.1016/j.petrol.2004.02.00610.1080/14697688.2010.481629

Bollerslev, T. (1986). Generalized Autoregressive Conditional Heteroskedasticity. Journal of Econometrics, 31, $307-$ 327. http://doi.org/10.1016/0304-4076(86)90063-1

Bouyé, E., Durrleman, V., Nikeghbali, A., Riboulet, G., \& Roncalli, T. (2000). Copulas for Finance: A Reading Guide and Some Applications. Manuscript, Financial Econometrics Research Center, 1-69. http://doi.org/10.1016/03044076(86)90063-110.2139/ssrn.1032533

Brandão, L., Dyer, J., \& Hahn, W. (2005). Using Binomial Decision Trees to Solve Real-Option Valuation Problems. Decision Analysis, 2 (2), 69-88. http://doi.org/10.1016/0304-4076(86)90063-110.1287/deca.1050.0040

Capéraà, P., \& Genest, C. (1993). Spearman's $\rho$ is larger than kendall's $\tau$ for positively dependent random variables. Journal of Nonparametric Statistics, 2 (2), 183-194. http://doi.org/10.1016/0304-4076(86)90063$110.1080 / 10485259308832551$

Chen, X., Fan, Y., \& Patton, A. (2004). Simple Tests for Models of Dependence Between Multiple Financial Time Series, with Applications to U.S. Equity Returns and Exchange Rates. London Economics Financial Markets Group Working Paper No. 483, 1-37.

Chen, W., Langrené, N., \& Tarnopolskaya, T. (2016). Optimal Natural Resource Extraction with Production Target: An Application in Mining. Annual International Conference. Real Options Group. Oslo/Trondheim, Norway.

Cherubini, U., \& Luciano, E. (2002). Bivariate Option Pricing with Copulas. Applied Mathematical Finance, 9 (2), 69-86. http://doi.org/10.1016/0304-4076(86)90063-110.1080/13504860210136721a

Cherubini, U., \& Luciano, E. (2002a). Multivariate Option Pricing with Copulas. ICER Working Papers - Applied Mathematics Series.

Cherubini, U., Luciano, E., \& Vecchiato, W. (2004). Copula Methods in Finance. Chichester: John Wiley \& Sons Limited. http://doi.org/10.1016/0304-4076(86)90063-1doi:10.1002/9781118673331

Chiou, S., \& Tsay, R. (2008). A Copula-based Approach to Option Pricing and Risk Assessment. Journal of Data Science, 6, 273-301.

Clayton, D. (1978). A model for association in bivariate life tables and its application in epidemiological studies of familial tendency in chronic disease incidence. Biometrika, 65 (1), 141-151. http://doi.org/10.2307/2335289

Copeland, T., \& Keenan, P. (1998). How much is flexibility worth? McKinsey Quarterly, 2, 38-49.

Copeland, T., \& Keenan, P. (1998a). Making Real Options Real. McKinsey Quarterly, 3, 129-141.

Cox, J., Ross, S., \& Rubinstein, M. (1979). Option Pricing: A Simplified Approach. Journal of Financial Economics, 7, 229-263. http://doi.org/10.1016/0304-405X(79)90015-1

Denault, M., Dupuis, D., \& Couture-Cardinal, S. (2009). Complementarity of hydro and wind power: Improving the risk profile of energy inflows. Energy Policy, 37 (12), 5376-5384. http://doi.org/10.1016/j.enpol.2009.07.064

Dixit, A., \& Pindyck, R. (1994). Investment under Uncertainty. Princeton, New Jersey: Princeton.

Dixit, A., \& Pindyck, R. (1995). The Options Approach to Capital Investment. Harvard Business Review, 5+6, 105115. 
Dockendorf, J., \& Paxson, D. (2010). Continuous Rainbow Options in Co-Integrated Markets. Annual International Conference. Real Options Group. Rome, Italy.

EIA. (2015). Monthly Natural Gas Prices. U.S. Energy Information Administration. Retrieved April 19, 2016 from https://www.eia.gov/naturalgas/data.cfm\#prices

Embrechts, P., MacNeil, A., \& Straumann, D. (2002). Correlation and Dependence in Risk Management: Properties and Pitfalls. In M. Dempster (Ed.), Risk management: value at risk and beyond (pp. 176-223). Cambridge: Cambridge University Press. http://doi.org/10.1145/844076.844084

Engle, R. (1982). Autoregressive Conditional Heteroscedasticity with Estimates of the Variance of United Kingdom Inflation. Econometrica, 50 (4), 987-1007. http://doi.org/10.2307/1912773

Fleten, S.-E., \& Näsäkkälä, E. (2010). Gas-fired power plants: Investment timing, operating flexibility and CO2 capture. Energy Economics, 32 (4), 805-816. http://doi.org/10.1016/j.eneco.2009.08.003

Frank, M. (1979). On the simultaneous associativity of $\mathrm{F}(\mathrm{x}, \mathrm{y})$ and $\mathrm{x}+\mathrm{y}-\mathrm{F}(\mathrm{x}, \mathrm{y})$. Aequationes Mathematicae, 19, 194-226.

Fréchet, M. (1957). Les Tableaux de Corrélation Dont Les Marges Sont Données. Annales de l'Université de Lyon, Sciences Mathématiques et Astronomie, 20, 13-31. http://doi.org/10.2307/1401672

Frees, E., \& Valdez, E. (1998). Understanding Relationships Using Copulas. North American Actuarial Journal, 2 (1), 1-25. http://doi.org/10.1080/10920277.1998.10595667

Georgiopoulos, N. (2017). Financing Uncertain Growth Options. Annual International Conference. Real Options Group. Boston, United States.

Glosten, L., Jagannathan, R., \& Runkle, D. (1993). On the Relation between the Expected Value and the Volatility of the Nominal Excess Return on Stocks. The Journal of Finance, 48 (5), 1779-1801. http://doi. org/10.1111/j.1540-6261.1993.tb05128.x

González, J., \& García, K. (2015, March 27). Pemex se retira de ductos para concentrarse en crudo. El Economista. Retrieved January 9, 2017 from http://eleconomista.com.mx/industrias/2015/03/27/pemex-se-retira-ductos-concentrarse-crudo

Grégoire, V., Genest, C., \& Gendron, M. (2008). Using copulas to model price dependence in energy markets. Energy Risk, March 62-68. http://doi.org/10.1.1.461.3276

Gumbel, E. (1960). Bivariate Exponential Distributions. Journal of the American Statistical Association, 55 (292), 698-707. http://doi.org/10.2307/2281591

Herath, H., Kumar, P., \& Amershi, A. (2011). Crack spread option pricing with copulas. Journal of Economics and Finance, 37 (1), 1-22. http://doi.org/10.1007/s12197-011-9171-1

Hoeffding, W. (1940). Massstabinvariante Korrelationstheorie. Schriften des Mathematischen Seminars und des Instituts für Angewandte Mathematik der Universität Berlin, 5 (3), 181-233.

Hung, M.-w., \& So, L.-c. (2011). The Role of Uncertainty in Real Options Analysis. Annual International Conference. Real Options Group. Turku, Finland.

Joe, H. (1997). Multivariate Models and Multivariate Dependence Concepts. London: Chapman \& Hall/CRC.

Johnson, H. (1987). Options on the Maximum or the Minimum of Several Assets. The Journal of Financial and Quantitative Analysis, 22 (3), 277-283. http://doi.org/10.2307/2330963

Kauppinen, L., Salo, A., \& Siddiqui. A.S. (2016). The Impact of Uncertain Revenues and Costs on Time-to-Build Projects: A Real Options Approach. Annual International Conference. Real Options Group. Oslo/Trondheim, Norway.

Kulatilaka, N. (1995). The Value of Flexibility: A General Model of Real Options. In L. Trigeorgis (Ed.), Real Options in Capital Investment-Models, Strategies, and Applications (pp. 89-108). Westport, Connecticut: Praeger.

Leslie, K., \& Michaels, M. (1997). The real power of real options. The McKinsey Quarterly, 3, 4-22.

Luehrman, T. (1998). Strategy as a portfolio of real options. Harvard Business Review, 9+10, 89-99.

Luehrman, T. (1998a). Investment opportunities as real options: getting started on the numbers. Harvard Business Review, 7+8, 51-67.

Majd, S., \& Pindyck, R. (1987). Time to Build, Option Value, and Investment Decisions. Journal of Financial Economics, 18, 7-27. http://doi.org/10.1016/0304-405X(87)90059-6.

Margrabe, W. (1978). The Value of an Option to Exchange One Asset for Another. Journal of Finance, 33 (1), 177186. http://doi.org/10.2307/2326358. 
Miranda, O., \& Brandão, L. (2014). Project and Firm Valuation in Mining Exploration: An Application in Peru. Annual International Conference. Real Options Group. Medellin, Colombia.

Mun, J. (2006). Real options analysis: tools and techniques for valuing strategic investments and decisions (2nd ed.). Hoboken, N.J.: John Wiley \& Sons.

Myers, S. (1984). Finance Theory and Financial Strategy. Interfaces, 14 (1), 126-137.

Nelsen, R. (1999). An Introduction to Copulas. New York: Springer Series in Statistics.

Olmos, R. (2017, April 6). Pemex publica contratos con Odebrecht pero censura los datos centrales. Animal Político. Retrieved June 2, 2017 from http://www.animalpolitico.com/2017/04/pemex-contratos-odebrecht-2/

Patton, A. (2006). Estimation of Multivariate Models for Time Series of Possibly Different Lengths. Journal of Applied Econometrics, 21, 147-173. http://doi.org/10.1002/jae.865

Patton, A. (2006a). Modelling asymmetric exchange rate dependence. International Economic Review, 47 (2), $527-$ 556. http://doi.org/10.1111/j.1468-2354.2006.00387.x

PEMEX. (2013). Principales elementos del plan de negocios de PEMEX y sus organismos subsidiarios. Petróleos Mexicanos. Retrieved January 14, 2016 from http://www.pemex.com/acerca/plan-de-negocios/Documents/pn_1418_131031.pdf

PEMEX. (2015). Presentación a Inversionistas. Mexico City: Petróleos Mexicanos. Retrieved January 14, 2016 from http://www.pemex.com/ri/herramientas/Presentaciones\%20Archivos/PEMEX\%20Presentacion\%20Inversionistas_150908.pdf

PEMEX. (2015a). Pemex monetiza su participación en Gasoductos de Chihuahua mediante la firma de un convenio con Ieno. Retrieved January 14, 2016 from http://www.pemex.com/saladeprensa/boletines_nacionales/Paginas/2015-072-nacional.aspx

PEMEX. (2016). Nota informativa 19 de mayo 2016: Circulación Interna. Mexico City: Petróleos Mexicanos.

Pimentel, P., Azevedo-Pereira, J., \& Couto, G. (2008). High Speed Rail Transport Valuation with Multiple Uncertainty Factors. Annual International Conference. Real Options Group. Turku, Finland.

Qiu, X., \& Wang, Z. (2014). Investment in Deep-water Oil \& Gas Exploration Projects: A Multi-Factor Analysis. Annual International Conference. Real Options Group. Medellin, Colombia.

Ross, S. (1995). Uses, Abuses, and Alternatives to the Net-Present-Value Rule. Financial Management, 24 (3), 96-102.

Sødal, S., Koekebakker, S., \& Aadland, R. (2008). Market switching in shipping - A real option model applied to the valuation of combination carriers. Review of Financial Economics, 17 (3), 183-203. http://doi.org/10.1016/j. rfe.2007.04.001

Sklar, A.W. (1959). Fonctions de répartition à n dimension et leurs marges. Publications de l'Institut de Statistique de l'Université de Paris, 8, 229-231. http://doi.org/10.12691/ijefm-3-2-3

Stulz, R. (1982). Options on the minimum or the maximum of two risky assets: Analysis and Applications. Journal of Financial Economics, 10, 161-185. http://doi.org/10.1016/0304-405X(82)90011-3

Tawn, J.A. (1998). Bivariate Extreme Value Theory: Models and Estimation. Biometrika, 75 (3), 397-415. http://doi. org/10.2307/2336591

Trigeorgis, L., \& Mason, S. (1987). Valuing Managerial Flexibility. Midland Corporate Finance Journal, 14-21.

Valizadeh Haghi, H., Tavakoli Bina, M., Golkar, M., \& Moghaddas-Tafreshi, S. (2010). Using Copulas for analysis of large datasets in renewable distributed generation: PV and wind power integration in Iran. Renewable Energy, 35 (9), 1991-2000. http://doi.org/10.1016/j.renene.2010.01.031

Westner, G., \& Madlener, R. (2010). Investment in New Power Generation under Uncertainty: Benefits of CHP vs Condensing Plants in a Copula-Based Analysis. FCN Working Paper No. 12/2010 Institute for Future Energy Consumer Needs and Behavior (FCN), 1-37.

Yan, J. (2007). Enjoy the Joy of Copulas: With a Package copula. Journal of Statistical Software, 21 (4), 1-21. http:// doi.org/10.18637/jss.v021.i04

Zakoian, J.-M. (1994). Threshold heteroskedastic models. Journal of Economic Dynamics and Control, 18 (5), 931 955. http://doi.org/10.1016/0165-1889(94)90039-6 